\title{
Prostaglandin- and Isoproterenol-Stimulated Cyclic AMP Accumulation in Rat Perinatal Lung Fibroblasts: Effects of Developmental Age
}

\author{
FERNANDO J. TEIXEIRA, MICHELE L. GIRASH BEVAN, AND DAVID M. OLSON
}

Departments of Paediatrics and Physiology, MRC Group in Fetal and Neonatal Health and Development, The University of Western Ontario, The Lawson Research Institute, St. Joseph's Health Centre,

London, Ontario, Canada T6G $2 R 7$

\begin{abstract}
The fibroblast of the fetal and neonatal lung is intimately involved with lung development and function. Additionally, the perinatal rat lung fibroblast is a significant source of prostaglandins (PG) $I_{2}$ and $E_{2}$, which in turn affect lung development and function. Their effects may be mediated by cAMP. We, therefore, tested both the relative effectiveness of PG and the $\beta$-adrenergic agonist, isoproterenol, and the developmental age sensitivity to these agonists on rat perinatal lung fibroblast cAMP accumulation. Confluent monolayer cultures of 3rd-passage fibroblasts ( $>95 \%$ purity) from $\mathrm{d}-3$ newborn rats responded in a concentration-dependent fashion to several PG $\left(10^{-8}\right.$ $\left.10^{-4} \mathrm{M}\right)$ and isoproterenol $\left(10^{-7}-2 \times 10^{-6} \mathrm{M}\right)$ by increasing cAMP accumulation. The rank order of responsiveness, in terms of maximum accumulated cAMP, were carba $\mathbf{P G I _ { 2 }}$ $>\mathrm{PGE}_{1}=\mathrm{PGI}_{2} \mathrm{Na}$ salt $=\mathrm{PGI}_{2}$ methyl ester $\gg \mathrm{PGE}_{2}>$ isoproterenol. At the 3 developmental d tested [d 20 fetus, d 1 newborn, and d 3 newborn (term = d 22)], $P_{G E}$, carba $\mathbf{P G I}_{2}$, and isoproterenol each elicited concentration-dependent increases in cAMP accumulation. Unstimulated cAMP levels were $2-5 \mathrm{fmol} / \mu \mathrm{g}$ protein $/ 15 \mathrm{~min}$ at all three ages. On d 20 of gestation, the highest accumulation achieved at the highest concentration tested was 30-70 $\mathrm{fmol} / \mu \mathrm{g}$ protein $/ 15 \mathrm{~min}$ for each agonist. There was no agedependent change in responsiveness to $\mathrm{PGE}_{2}$. Carba $\mathbf{P G I}_{2-}$ stimulated cAMP accumulation increased from d 20 of gestation with each advancing age tested to approximately 15-fold by d 3 newborn. Isoproterenol stimulated a 2- to 3fold increase in maximum cAMP accumulated between the d-20 fetus and d-1 newborn, but no further increase occurred at $\mathrm{d} 3$. These data demonstrate that in perinatal rat lung fibroblasts the most prevalent endogenous $\mathbf{P G}, \mathrm{PGI}_{2}$, stimulates the greatest accumulation of cAMP, and this responsiveness increases substantially with perinatal development. The implications in terms of lung development and function require resolution. (Pediatr Res 31: 344-348, 1992)
\end{abstract}

Abbreviations

IBMX, 3-isobutyl 1-methylxanthine PG, prostaglandin

Received June 24, 1991; accepted November 27, 1991

Correspondence: D. M. Olson, Ph.D., Director, Centre for Research in Maternal Fetal and Newborn Health, University of Alberta, 1D1 Walter C. Mackenzie Health Sciences Centre, Edmonton, Alberta, Canada T6G 2R7.

Supported by the Medical Research Council of Canada (Group GrantD.M.O.), Easter Seals Research Institute of Ontario (Studentship-M.L.G.B.), an Ontario Thoracic Society Block Term Grant (D.M.O.), the Lawson Research Institute Pooled Research Trust (D.M.O.), and the Child Health Research Institute, London, Ontario.
The fibroblast of the fetal and neonatal lung is an important cell in normal and abnormal lung function and development. In rats, it responds to glucocorticoid stimulation with the production of fibroblast pneumocyte factor (1), which in turn stimulates pneumocyte choline-phosphate cytidylyltransferase activity (2). Also, fibroblasts are a source of extracellular matrix proteins, especially collagen types I and III $(3,4)$, and thereby contribute to the morphology of the developing lung and its mechanical function.

Perinatal rat lung fibroblasts produce a number of $\mathrm{PG}$ in vitro (5). The most prevalent of these is prostacyclin $\left(\mathrm{PGI}_{2}\right)$, as determined by its hydrolysis metabolite, 6-keto- $\mathrm{PGF}_{1 \alpha}$. $\mathrm{PGE}_{2}$ is also produced by these cells, although at levels only about $25-30 \%$ of those of $\mathrm{PGI}_{2} . \mathrm{PGF}_{2 \alpha}$ is produced only at low rates. The ability of the fibroblast to produce $\mathrm{PG}$ is similar to that of perinatal rat lung endothelial cells, pneumocytes, $(5,6)$ or mixed lung cells (6).

$\mathrm{PG}$ are known to have autocrine and paracrine actions in the lung. $\mathrm{PGE}_{\text {, }}$ inhibits fibroblast proliferation and collagen synthesis in human fetal lung fibroblasts (7). It is probable, therefore, that fibroblast PG may act in an autocrine or paracrine fashion to affect fibroblast function. One way by which PG effects upon the fibroblast may be mediated is via the second messenger, cAMP. Skinner et al. (8) demonstrated that $\mathrm{PGE}_{2}$ stimulates changes in adenylate cyclase activity in fetal rat lung fibroblasts. Moreover, they found that cortisol enhances this responsiveness of fibroblasts to $\mathrm{PGE}_{2}$, which is suggestive of a maturational change induced by late gestational increases in circulating glucocorticoids. The purpose of this study, therefore, was to examine the responsiveness of perinatal rat lung fibroblasts, in terms of cAMP accumulation, to PG and the $\beta$-adrenergic agonist, isoproterenol, at three different ages during a period of rapid pulmonary development.

\section{MATERIALS AND METHODS}

Materials. Waymouth's Medium:Dulbecco's Minimal Essential Medium (1:1, vol/vol) (medium), FCS, $0.05 \%$ trypsin (cata$\log$ no. $610-5300 \mathrm{AG}$ ), and $0.2 \%$ EDTA were purchased from Gibco Canada, Burlington, Ontario, Canada. Isoproterenol (Isuprel) was obtained from Winthrop Pharmaceuticals, Aurora, Ontario, Canada. Iodinated ${ }^{125} \mathrm{I}$-cAMP and its antisera were a kind gift from Dr. D. Armstrong, Department of Obstetrics and Gynaecology and Physiology, University of Western Ontario (9). The following items were purchased from Sigma Chemical Co., St. Louis, MO: cAMP free standard, BSA, IBMX, and DNase (catalog no. D4263). $\mathrm{PGE}_{1}, \mathrm{PGE}_{2}$, carba prostacyclin, and prostacyclin sodium salt were purchased from Cayman Chemical Company, Ann Arbor, MI. Prostacyclin methyl ester was purchased from Upjohn Co., Kalamazoo, MI.

Fibroblast cell culture preparation. Monolayer cultures of fi- 
broblast lung cells were prepared from perinatal rat pups at $\mathrm{d} 20$ of gestation (term $=22 \mathrm{~d}$ ), newborn d 1 , or $\mathrm{d} 3$, according to the procedure described by Tanswell et al. (10). Briefly, timed pregnant rats (Long Evans $\times$ Sprague-Dawley, Charles River, Canada) were killed by excess chloroform, and the pups were decapitated in utero. Newborn pups were killed by decapitation. Midline thoracic incisions were made, and the lungs were removed. Lung tissues were placed in Dulbecco's PBS. The heart, vascular tissue, and airways were cut away, and the lungs were minced into $2-\mathrm{mm}^{3}$ fragments. Cells were dispersed from the tissue by stirring in sterile $0.05 \%$ trypsin containing $0.2 \%$ EDTA and 50 $\mu \mathrm{g} / \mathrm{mL}$ DNase for $15 \mathrm{~min}$. The protease activity was stopped with $10 \%$ FCS (growth medium). The cells were then filtered through porous $(100-\mu \mathrm{m})$ sterile nylon cloth, resuspended in 15 $\mathrm{mL}$ of growth medium, and centrifuged (Sorvall) for $15 \mathrm{~min}$ at $1500 \mathrm{rpm}$ at ambient temperature. The supernatant was removed, and the cells were resuspended in $10 \mathrm{~mL}$ of growth medium. The cells from an entire preparation were plated in a $\mathrm{T}_{80}$ flask (Corning) and incubated at $37^{\circ} \mathrm{C}$ for $1 \mathrm{~h}$ to allow for fibroblast adhesion. After this time, the cells were rinsed and reincubated with $10 \mathrm{~mL}$ growth medium at $37^{\circ} \mathrm{C}$ in a gas mixture consisting of $1 \% \mathrm{O}_{2}, 5 \% \mathrm{CO}_{2}$, and the balance $\mathrm{N}_{2}$. This procedure produces a medium $\mathrm{PO}_{2}$ of $4 \pm 0.5 \mathrm{kPa}$, which is close to the $\mathrm{PO}_{2}$ of fetal plasma (approximately $2.7 \mathrm{kPa}$ ) (6). All cells from fetal and neonatal lungs were grown at $1 \% \mathrm{O}_{2}$ to maintain uniformity of procedure with all groups. Previous studies have shown that fetal rat lung fibroblasts have the greatest proliferation rate at $1 \%$ $\mathrm{O}_{2}(11)$.

Media were changed every $48 \mathrm{~h}$ until confluence was reached (5-7 d after plating) as determined by phase contrast microscopy. At confluence, the cells were released from the flask $(0.05 \%$ trypsin), resuspended in fresh growth medium, split in a $1: 3$ ratio, and replated. This procedure was repeated to obtain 3rd-passage cells, which were plated in $6 \times 4$ well plates of $2 \mathrm{~cm}^{2}$ each for experimentation. Each well contained approximately 15000 cells $/ \mathrm{cm}^{2}$ as determined by automated cell counting (Coulter Electronics, Hialeah, FL). The purity of these cultures are $>95 \%$ fibroblasts (5).

The housing and handling of animals for this study was in strict adherence to the guidelines of the Canadian Council of Animal Care and was performed with the approval of the University Council on Animal Care.

Experimental protocols. At confluence and $24 \mathrm{~h}$ before experimentation, the media were removed and replaced with serumfree medium. All PG and isoproterenol were dissolved in Hanks' buffered saline solution containing $20 \mu \mathrm{M} \mathrm{N}$-2-hydroxyethylpiperazine- $N^{\prime}$-2-ethanesulfonic acid ( $\mathrm{pH} \mathrm{7.38)}$ and the phosphodiesterase inhibitor IBMX $\left(10^{-4} \mathrm{M}\right)$. At the beginning of each experiment, serum-free medium was removed from the fibroblasts and replaced by Hanks' buffered saline solution with or without agonists. After a $15-\mathrm{min}$ incubation period at $37^{\circ} \mathrm{C}$ in a water bath in room air, reactions were stopped by microwaving the cells (high power) for $42 \mathrm{~s}$. Media were either frozen at $-20^{\circ} \mathrm{C}$ for later assay or immediately assayed for cAMP and total protein.

Assays. Protein assays were performed using the Bradford technique (12) with BSA as the standard. cAMP determinations were made directly from the medium according to the RIA procedure of Brooker (13). Samples $(200 \mu \mathrm{L})$ were acetylated with $15 \mu \mathrm{L}$ of triethylamine:acetic anhydride $(2: 1)$ before assaying to enhance RIA sensitivity. Inasmuch as the cells released their cAMP into the medium upon boiling, the medium contained both cellular and released cAMP. The results reflect total cAMP accumulated during the incubation. The cAMP RIA has been validated and characterized by Reddoch et al. (9).

Statistical analysis. Values are expressed as fmol cAMP $/ \mu \mathrm{g}$ protein $/ 15 \mathrm{~min}$. Results are expressed as mean $\pm \mathrm{SD}$ of three separate experiments. Each experiment was performed on cells obtained from separate litters of pups (five to 13 pups/litter) with four replications at each agonist concentration tested from each litter. The number of litters used in each experiment is described in the figure legends. The data in Figure 1 were analyzed separately for each agonist using one-way analysis of variance. In Figures 2 through 4, the data were analyzed by a nested analysis of variation, in which the variation within each litter was divided between developmental age and dose of agonist and nested within replicate litters. When differences were identified by a significant $F$ value, Tukey's test was used to determine age, dose, or interaction differences. Significance was achieved at $p<0.05$.

\section{RESULTS}

The effects of PG and isoproterenol on cAMP accumulation in newborn d-3 rat lung fibroblasts are illustrated in Figure 1.
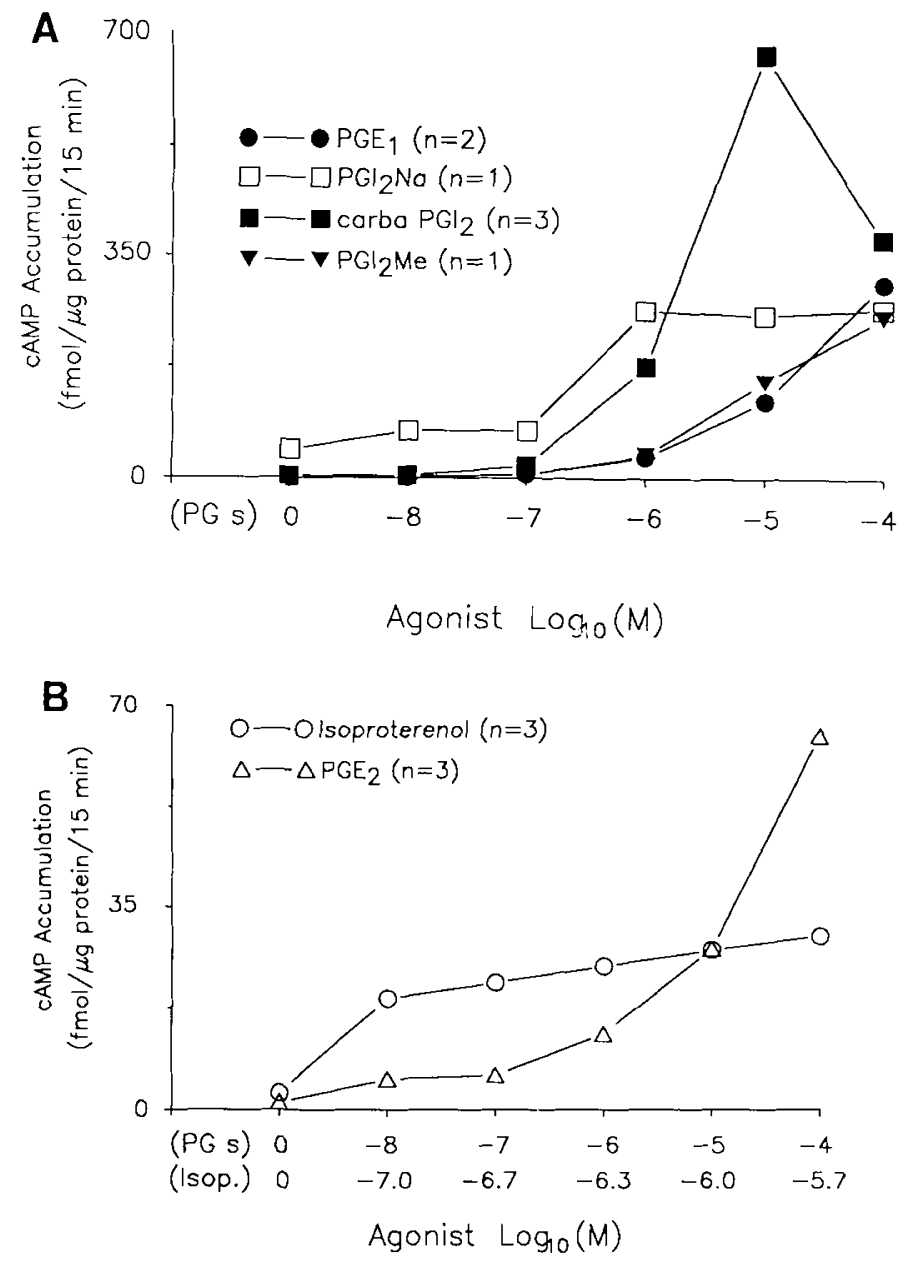

Fig. 1. $A$, The effect of various $P G$ on cAMP accumulation leveis in newborn $\mathrm{d} 3$ rat lung fibroblasts. Confluent fibroblasts were incubated with different concentrations of $\mathrm{PGE}_{s}, \mathrm{PGI}_{2} \mathrm{Me}$, carba $\mathrm{PGI}_{2}$, or $\mathrm{PGI}_{2} \mathrm{Na}$ for $15 \mathrm{~min}$. cAMP accumulation is expressed as fmol cAMP $/ \mu \mathrm{g}$ protein/ 15 min incubation. Data for each agonist are expressed as the mean of the number of separate experiments indicated in parentheses, with each experiment containing four replicates. For clarity, the SD variation bars have been omitted, but the values never exceeded $10 \%$ of the mean. A $10^{-7}-\mathrm{M}$ concentration stimulated significant $(p<0.05)$ increases in cAMP accumulation in all agonists tested. $B$, The effect of $\mathrm{PGE}_{2}$ and the $\beta$ adrenergic agonist, isoproterenol, on cAMP accumulation levels in newborn d-3 rat lung fibroblasts. Confluent fibroblasts were incubated with different concentrations of $\mathrm{PGE}_{2}$ and isoproterenol for $15 \mathrm{~min}$. cAMP accumulation is expressed as fmol cAMP/ $\mu \mathrm{g}$ protein $/ 15 \mathrm{~min}$ incubation. Data for each agonist are expressed as the mean of the number of three separate experiments indicated in parentheses, with each experiment containing four replicates. For clarity, the SD variation bars have been omitted, but the values never exceeded $10 \%$ of the mean. At $10^{-7} \mathrm{M}$, all agonists tested stimulated significant $(p<0.05)$ increases in cAMP accumulation. 


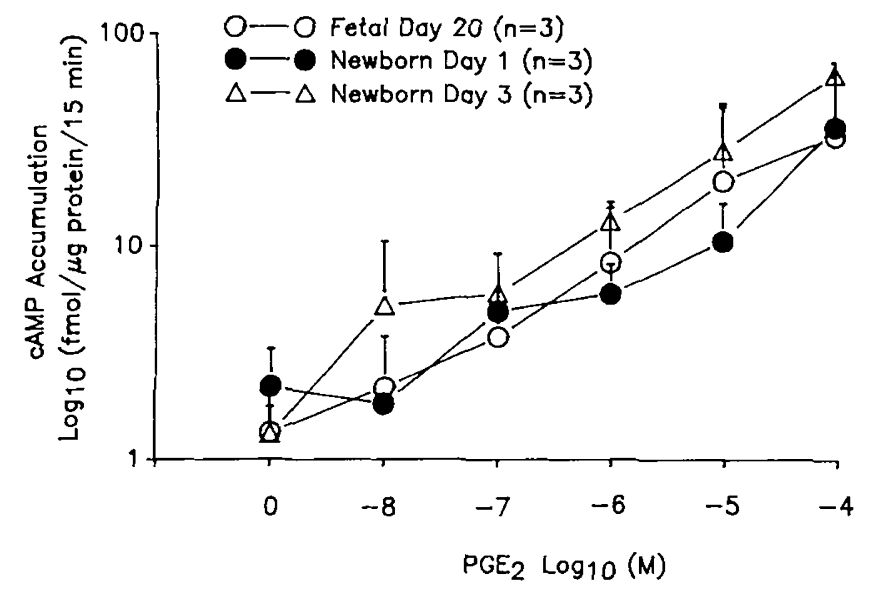

Fig. 2. The effect of developmental age on $\mathrm{PGE}_{2}$-stimulated cAMP accumulation in perinatal rat lung fibroblasts. Confluent fibroblasts were incubated with increasing concentrations of $\mathrm{PGE}_{2}$ at fetal d 20, newborn d 1 , and newborn $\mathrm{d} 3$ for $15 \mathrm{~min}$. cAMP accumulation is expressed as $\mathrm{fmol} \mathrm{cAMP} / \mu \mathrm{g}$ protein $/ 15$ min incubation. Each point is the mean \pm SD of results from three separate experiments, each consisting of four replicates. Note that the ordinate is in log scale. Increasing $\mathrm{PGE}_{2}$ concentrations stimulated a significant increase in cAMP accumulation $(p<$ 0.05 ). There was no statistical difference in cAMP accumulation because of the developmental age of the fibroblasts.

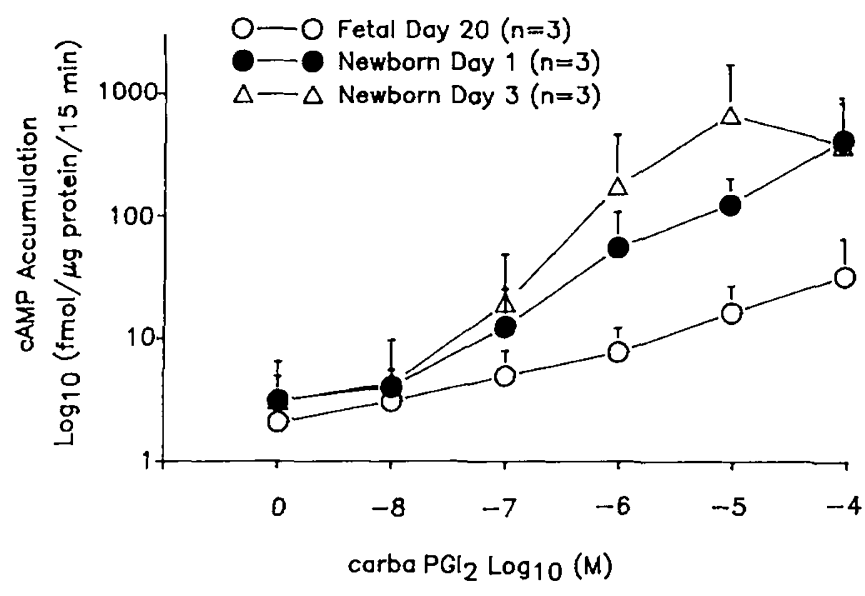

Fig. 3. The effect of developmental age on carba $\mathrm{PGI}_{2}$-stimulated cAMP accumulation in perinatal rat lung fibroblasts. Confluent fibroblasts were incubated with increasing concentrations of carba $\mathrm{PGI}_{2}$ at fetal d 20, newborn d 1 , and newborn d 3 for $15 \mathrm{~min}$. cAMP accumulation is expressed as fmol cAMP $/ \mu \mathrm{g}$ protein $/ 15 \mathrm{~min}$ incubation. Each point is the mean $\pm \mathrm{SD}$ of results from three separate experiments, each consisting of four replicates. Note that the ordinate is in log scale. Also, there was a significant increase in cAMP accumulation because of the developmental age of fibroblasts so that $\mathrm{d} 3>\mathrm{d} 1>\mathrm{d} 20(p<0.05)$. Increasing carba $\mathrm{PGI}_{2}$ concentrations stimulated a significant increase in cAMP accumulation $(p<0.05)$

All agonists tested elicited concentration-dependent increases in cAMP levels $(p<0.05)$. Increases in cAMP accumulation may be a reflection of either increased cAMP synthesis or decreased cAMP degradation. Because fibroblasts were incubated in the presence of the phosphodiesterase inhibitor, IBMX, the increases observed most probably represent an increase in cAMP production. For each PG tested, $10^{-7} \mathrm{M}$ stimulated a significant increase $(p<0.05)$ in cAMP accumulation over control (no PG) values. $\mathrm{PGE}_{1}$ and the analogues of $\mathrm{PGI}_{2}$ were more effective stimulators of cAMP accumulation than $\mathrm{PGE}_{2}$. For these agonists, the highest cAMP levels achieved at the highest concentrations tested were consistently in the $300-\mathrm{fmol} / \mu \mathrm{g}$ protein $/ 15 \mathrm{~min}$ range. Carba $\mathrm{PGI}_{2}$ was the most potent stimulator among the prosta-

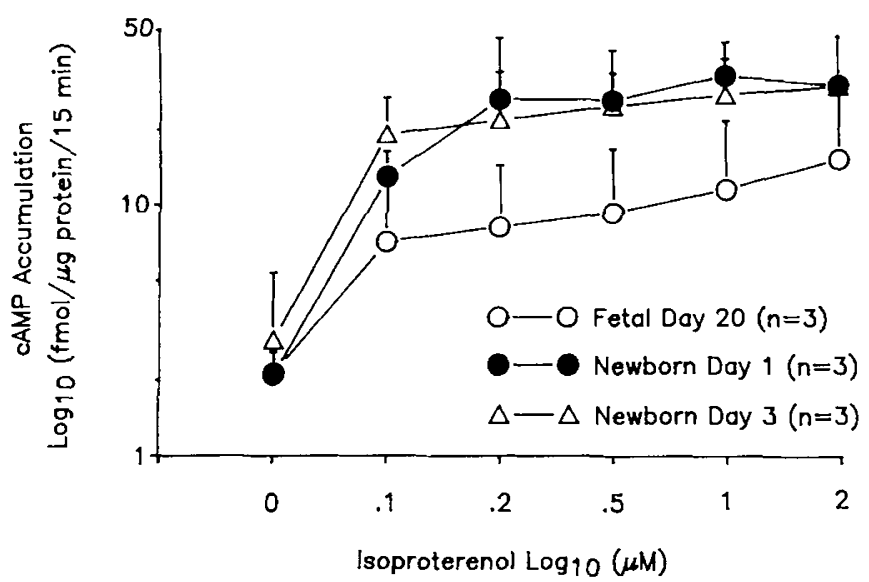

Fig. 4. The effect of developmental age on isoproterenol-stimulated cAMP accumulation in perinatal rat lung fibroblasts. Confluent fibroblasts were incubated with increasing concentrations of isoproterenol at fetal d 20, newborn d 1 , and newborn d 3 for 15 min. cAMP accumulation is expressed as fmol cAMP/ $\mu \mathrm{g}$ protein $/ 15 \mathrm{~min}$ incubation. Each point is the mean $\pm \mathrm{SD}$ of results from three separate experiments, each consisting of four replicates. Note that the ordinate is in log scale. Increasing isoproterenol concentrations stimulated a significant increase in cAMP accumulation $(p<0.05)$. Day 1 newborn responses were statistically greater than $\mathrm{d} 20$ fetal responses $(p<0.05)$, but there was no further increase in $\mathrm{d} 3$ fibroblasts.

cyclin analogues, with levels reaching approximately $700 \mathrm{fmol} /$ $\mu \mathrm{g}$ protein $/ 15 \mathrm{~min}$. $\mathrm{PGE}_{2}$ and isoproterenol were less effective stimulators of cAMP accumulation. Although concentrationdependent increases in cAMP accumulation were observed, the highest accumulation levels were 10 times less than those elicited by $\mathrm{PGE}_{1}$ and the prostacyclin analogs at the same agonist concentrations.

To elucidate the effects of advancing developmental age on fibroblast responses to $\mathrm{PG}, \mathrm{PGE}_{2}$ and carba $\mathrm{PGI}_{2}$ were administered to pulmonary fibroblasts cultured from rats at three different ages in the perinatal period: $\mathrm{d} 20$ gestational age and $\mathrm{d} 1$ and d 3 newborn (Figs. 2 and 3). Both PG elicited concentrationdependent responses at all ages tested $(p<0.05)$. The fibroblast responsiveness to $\mathrm{PGE}_{2}$ and carba $\mathrm{PGI}_{2}$ was similar in $\mathrm{d} 20$ fibroblasts in terms of the highest levels of cAMP accumulation achieved. The overall responsiveness of fibroblasts to $\mathrm{PGE}_{2}$ was not statistically different at the ages tested. However, the ability of carba $\mathrm{PGI}_{2}$ to stimulate cAMP accumulation increased with advancing developmental age $(p<0.05)$, so that newborn $\mathrm{d} 3>$ newborn d $1>$ fetal d 20 .

Another receptor-mediated mechanism for activating adenylate cyclase is $\beta$-adrenergic receptor activation. We therefore examined the effects of the $\beta$-adrenergic agonist, isoproterenol, on cAMP accumulation in fibroblasts obtained during fetal and early neonatal development and compared these results with the effects of PG. Figure 4 illustrates the responses elicited for the fetal d-20, newborn d-1, and newborn d-3 cells. Significant ( $p<$ $0.05)$ age- and concentration-dependent increases in cAMP accumulation were evident, and an age-dependent increase $(p<$ 0.05 ) occurred between d 20 of fetal life and newborn $d 1$. The relative ability of isoproterenol to stimulate cAMP accumulation was less than that of the PG tested. By $\mathrm{d} 3$, maximum fibroblast production of cAMP by the $\beta$-adrenergic agonist was $1 / 20$ that of the greatest effects observed with $\mathrm{PGI}_{2}$ and $1 / 2$ that of $\mathrm{PGE}_{2}$ at the highest agonist concentrations tested.

\section{DISCUSSION}

The cultured perinatal rat lung fibroblast produces large amounts of prostacyclin and smaller amounts of $\mathrm{PGE}_{2}$ (5). Under conditions in which endogenous arachidonic acid release is stim- 
ulated by the calcium ionophore, $\mathrm{A} 23187, \mathrm{PGI}_{2}$ production by fibroblasts can increase 60 -fold. Because PG may act on the fibroblast in an autocrine or paracrine fashion to affect pulmonary development, the responsiveness of the fibroblast to changes in PG concentrations merits examination. Many cells respond to PG by altering their intracellular concentrations of cAMP. Therefore, we studied the concentration-dependent and developmental age-dependent accumulation of cAMP in perinatal rat lung fibroblasts to exogenous PG and compared these results with isoproterenol, which increases cAMP production by a separate receptor. The results presented demonstrate both PG- and isoproterenol-dependent cAMP accumulation in perinatal rat lung fibroblasts as a result of acute in vitro exposure. $\mathrm{PGE}_{1}$ and the three analogues of prostacyclin evoked larger responses than either $\mathrm{PGE}_{2}$ or isoproterenol. Each $\mathrm{PGI}_{2}$ analogue elicited a large cAMP response, which indicates that the cell was responding to prostacyclin rather than the salt or stabilizing moiety of the molecule. A similar pattern of adenylate cyclase responsiveness to different PG was observed by Powell and Solomon (14) in particulate fractions from $29-\mathrm{d}$ fetal (term $=31 \mathrm{~d}$ ) rabbit lungs. They also observed that $\mathrm{PGE}_{1}$ and $\mathrm{PGI}_{2}$ stimulated adenylate cyclase activity more than $\mathrm{PGE}_{2}$ or other PG. They did not test the effects of any $\beta$-adrenergic agonist.

The minimum concentration at which each PG stimulated a significant increase in cAMP accumulation over baseline was between $10^{-8}$ and $10^{-7} \mathrm{M}$. Prostacyclin concentrations of this magnitude are achieved in cell culture by fibroblasts stimulated with A23187 or arachidonic acid (5). Interestingly, in other experiments performed in our laboratory, it has been observed that $\mathrm{PGI}_{2}$ has an inhibitory effect on fibroblast proliferation at $10^{-9} \mathrm{M}(15)$. Therefore, if the effect of $\mathrm{PGI}_{2}$ on proliferation is cAMP-mediated, it may suggest that PG causes production of cAMP in excess of the amount required for the biologic response.

These data infer the existence of a prostacyclin receptor in rat perinatal lung fibroblasts. Studies by Dutta-Roy and Sinha (16) document the presence of a single PG receptor that binds PGE $_{1}$ and prostacyclin in human platelets. Occupancy of this receptor results in activation of adenylate cyclase. Interestingly, these investigators found that $\mathrm{PGE}_{2}$, unlike $\mathrm{PGI}_{2}$, did not compete with ${ }^{3} \mathrm{H}-\mathrm{PGE}_{1}$ for occupation of the $\mathrm{PGE}_{1} / \mathrm{PGI}_{2}$ receptor, suggesting that $\mathrm{PGE}_{2}$ has a low binding affinity for this receptor. Another study (17) also reported the existence of a $\mathrm{PGE} / \mathrm{PGI}_{2}$ receptor in bovine adrenal medulla cells, although different PGE classes were not tested for their binding parameters. Additionally, these investigators suggest that this receptor is functionally associated with a pertussis toxin-insensitive $G$ protein and not directly coupled to adenylate cyclase. Alternatively, Gardiner (18) suggests, based on a number of studies in several tissues and species, that three PGE receptor subtypes exist.

The results observed in our study could be explained by either receptor scheme. In the first instance, the roughly equivalent stimulation in cAMP accumulation observed with $\mathrm{PGE}_{1}$ and the prostacyclin analogs may be brought about by the binding of prostacyclin analogs and $\mathrm{PGE}_{1}$ to the same receptor. Each agonist would have similar efficacy for this receptor. The lower level of stimulation of cAMP accumulation by $\mathrm{PGE}_{2}$ may be the result of a lower affinity and/or decreased efficacy of $\mathrm{PGE}_{2}$ to this receptor. Conversely, the second possibility would be that $\mathrm{PGE}_{1}$ and the prostacyclin analogs bind to the same PGE receptor subtype, whereas $\mathrm{PGE}_{2}$ binds to a second $\mathrm{PGE}$ receptor subtype. With the experiments performed in this study, we were unable to distinguish between these two possibilities.

Our data demonstrate that the perinatal rat lung fibroblast increases its responsiveness to both prostacyclin and a $\beta$-adrenergic agonist with advancing development. The PG response was specific for $\mathrm{PGI}_{2}$ and significant increases occurred between fetal $\mathrm{d} 20$ and newborn $\mathrm{d} 1$ and again between newborn $\mathrm{d} 1$ and d 3. Powell and Solomon (14) described a developmental agedependent stimulation of adenylate cyclase activity in whole fetal and neonatal rabbit lung particulate fractions by $\mathrm{PGE}_{1}$. The response to $P G E_{1}$ increased significantly by $\mathrm{d} 24$ of gestational age compared with d 21 and increased further until d 27, where it remained constant until newborn $\mathrm{d} 3$ and then increased further until $d 8$. Therefore, this response is probably more related to lung development than to the process of birth, inasmuch as there are increases in responsiveness after parturition.

The $\mathrm{PGI}_{2}$ response differed from the isoproterenol response in two ways. First, there was no subsequent increase in the isoproterenol response between newborn $\mathrm{d} 1$ and $\mathrm{d} 3$. Second, although the ability of $10^{-6} \mathrm{M}$ carba $\mathrm{PGI}_{2}$ and isoproterenol to stimulate cAMP accumulation was the same on fetal $\mathrm{d} 20$, by newborn $\mathrm{d}$ 3 , carba $\mathrm{PGI}_{2}$ could stimulate six times more cAMP accumulation than isoproterenol at this concentration. The mechanisms responsible for these observations are unknown. Clearly, candidate steps include changes in receptor number and/or affinity, the relative influence of stimulatory and inhibitory $G$ proteins, or altered coupling of the receptor-G protein-adenylate cyclase complex (19).

More than just understanding the level of receptor-transduction coupling at which changes occur to account for these observations, it is important to understand the causes of changes in the receptor-transduction coupling mechanism. The increased responsiveness of the fibroblast to prostacyclin and isoproterenol may be related to lung maturation. Central to lung maturation are the changes in the circulating levels of glucocorticoids and the expression of glucocorticoid receptors (20). Endogenous or exogenous glucocorticoids mature late gestation fetal lungs (21$24)$. Dexamethasone increases the concentration of $\beta$-adrenergic receptors in both rabbit and rat fetal lung explant tissue $(25,26)$. In fetal d 19 cultured rat fibroblasts, cortisol treatment enhanced the responsiveness of adenylate cyclase to adrenalin and $\mathrm{PGE}_{2}$ (8) and $\mathrm{PGI}_{2}$ (27). Therefore, it is possible that in vivo changes in circulating glucocorticoids, or in the responsiveness to glucocorticoids, are responsible, in part, for the age-dependent increases in cAMP accumulation in response to prostacyclin and isoproterenol in vitro that we observed. Other factors that contribute to fetal lung maturation, such as simulated fetal breathing movements (28), thyroid hormones (29), IGF-I, and IGF-II (30, 31 ), may act synergistically with cortisol to enhance the responsiveness of the fibroblast to PG. This may account for the observed difference in the relative ability of PG to stimulate cAMP accumulation in our present experimental paradigm compared with that of previous studies $(8,27)$ in which cortisol only was studied.

The importance of the role of prostacyclin, which generated the greatest cAMP response, in the functioning of the fibroblast remains to be elucidated. It may be related to the morphologic aspects of lung maturation during the perinatal period, inasmuch as carba $\mathrm{PGI}_{2}$ slows the rate of fibroblast proliferation (14).

Acknowledgment. The authors thank Cathy Ochman for typing the manuscript.

\section{REFERENCES}

1. Smith BT, Giroud CJP 1975 Effects of cortisol on serially propagated fibroblast cell cultures derived from the rabbit fetal lung and skin. Can J Physiol Pharmacol 53:1037-1041

2. Post M, Barsoumian A, Smith BT 1986 The cellular mechanism of giucocorticoid acceleration of fetal lung maturation. Fibroblast-pneumonocyte factor stimulates choline-phosphate cytidylyltransferase activity. J Biol Chem 261:2179-2184

3. Baum BJ, Moss J, Breul SD, Crystal RG 1978 Association in normal human fibroblasts of elevated levels of adenosine $3^{\prime}: 5^{\prime}$-monophosphate with a selective decrease in collagen production. J Biol Chem 253:3391-3394

4. Berg RA, Moss J, Baum BJ, Crystal RG 1980 Regulation of collagen production by the $\beta$-adrenergic system. J Clin Invest $67: 1457-1462$

5. Olson DM, Tanswell AK 1989 Production of prostaglandins by fetal rat type II pneumocytes and fibroblasts. Biochim Biophys Acta 1003:327-330

6. Oison DM, Tanswell AK 1987 The effects of oxygen, calcium ionophore, and arachidonic acid on prostaglandin production by monolayer cultures of mixed cells and endothelial cells from rat fetal lungs. Exp Lung Res 12:207221

7. Barile FA, Ripley C, Siddiqui Z, Bienkowski RS 1988 Effects of prostaglandin 
$E_{1}$ on collagen production and degradation in human fetal lung fibroblasts Arch Biochem Biophys 256:441-446

8. Skinner SJM, Lowe C, Ashby CJ, Liggins GC 1989 Effects of corticosteroids, prostaglandin $\mathrm{E}$, and beta-agonists on adenylate cyclase activity in fetal rat lung fibroblasts and type ll epithelial cells. Exp Lung Res 15:335-343

9. Reddoch RB, Pelletier RM, Barbe GJ, Armstrong DT 1986 Lack of ovarian responsiveness to gonadotropic hormones in infantile rats sterilized with busulfan. Endocrinology 119:879-886

10. Tanswell AK, Fraher LJ, Grose EC 1989 Circulating factors that modify lung cell DNA synthesis following exposure to inhaled oxidants. I. Effect of serum and lavage on lung fibroblasts following exposure of adult rats to $1 \mathrm{ppm}$ ozone. J Toxicol Environ Health 27:239-254

11. Tanswell AK, Olson DM, Freeman BA 1990 Response of fetal rat lung fibroblasts to elevated oxygen concentrations after liposome-mediated augmentation of antioxidant enzymes. Biochim Biophys Acta 1044:269-274

12. Bradford M 1976 A rapid and sensitive method for the quantitation of microgram quantities of protein utilizing the principle of protein dye binding. Anal Biochem 72:248-254

13. Brooker G, Harper FJ, Terasaki WL, Moylan RD 1979 Radioimmunoassay of cyclic AMP and cyclic GMP. Adv Cyclic Nucleotide Res 10:1-33

14. Powell WS, Solomon S 1980 Effects of prostaglandins on the adenylate cyclase activity of lungs from fetal rabbits. Endocrinology 107:1469-1472

15. Girash Bevan ML, Olson DM 1991 Eicosanoids alter fetal rat lung fibroblast proliferation. Pediatr Res 29:318a(abstr)

16. Dutta-Roy AK, Sinha AK 1987 Purification and properties of prostaglandin E/prostacyclin receptor of human blood platelets. J Biol Chem 262:1268512691

17. Negishi $M$, Ito $S$, Tanaka T, Yokohama $H$, Hayashi $H$, Katada T, Ui M Hayaishi O 1987 Covalent cross-linking of prostaglandin E receptor from bovine adrenal medulla with a pertussis toxin-insensitive guanine nucleotidebinding protein. J Biol Chem 262:12077-12084

18. Gardiner PJ 1990 Classification of prostanoid receptors. In: Samuelsson B, Dahlen SE, Fritsch J, Hedquist P (eds) Advances in Prostaglandin, Thromboxane and Leukotriene Research. Raven Press, New York, pp 110-118

19. Roberts JM, Musci J 1986 Alveolar $\beta$-adrenoreceptors: modulation and role in perinatal adaptation. In: Johnston BM, Gluckman PD (eds) Respiratory
Control and Lung Development in the Fetus and Newborn. Perinatology Press, Ithaca, NY, pp 135-160

20. Sweezy NB, Buch SJ, Rae S, Mawdsley C, Post M 1989 Glucocorticoid receptor and surfactant protein expression in maturing rat lung. Pediatr Res 25:61 A(abstr)

21. Bailard PL 1982 Hormonal aspects of fetal lung development. In: Farrell PM (ed) Lung Development. Biological and Clinical Perspectives, Vol II. Academic Press, New York, pp 205-253

22. Hitchcock KR 1979 Hormones and the lung. I. Thyroid hormones and glucocorticoids in lung development. Anat Rec 194:15-40

23. Kitterman JA 1984 Fetal lung development. J Dev Physiol 6:67-82

24. Liggins GC, Howie RN 1972 A controlled trial of antipartum glucocorticoid treatment for prevention of the respiratory distress syndrome in premature infants. Paediatrics 50:515-525

25. Giannopouios G, Smith SK 1982 Hormonal regulation of beta-adrenergic receptors in fetal rabbit lung in organ culture. Life Sci 31:795-802

26. Maniscalco WM, Shapiro DL 1983 Effects of dexamethasone on beta-adrenergic receptors in fetal lung explants. Pediatr Res 17:959-965

27. Skinner SJM, Somervell CE, Lowe C 1991 Interaction between prostacyclin and cortisol in fetal lung cells: effects on cAMP production. Prostaglandins 41:331-343

28. Skinner SJM 1989 Fetal breathing movements: a mechanical stimulus for fetal lung cell growth and differentiation. In: Gluckman PD, Johnston BM, Nathanielsz PW (eds) Advances in Fetal Physiology: Review in Honor of Nathanielsz PW (eds) Advances in Fetal Physiology: R
GC Liggins. Perinatology Press, Ithaca, NY, pp 133-151

29. Liggins GC, Schellenberg J-C 1986 Hormones and lung maturation. In: Johnston BM, Gluckman PD (eds) Respiratory Control and Lung Development in the Fetus and Newborn. Perinatology Press, Ithaca, NY, pp 107-133

30. Han VKM, D'Ercole AJ, Lung PK 1987 Cellular localization of somatomedin (insulin-like growth factor) messenger RNA in the human fetus. In: Gluckman PD, Johnston BM, Nathanielsz PW (eds) Advances in Fetal Physiology: Reviews in Honor of GC Liggins. Perinatology Press, Ithaca, NY, pp 133151

31. Han VKM Hill DJ Strain AJ, Towle AC Iauder JM, Underwood LE D'Ercole AJ 1987 Identification of somatomedin/IGF immunoreactive cells in the human fetus. In: Gluckman PD, Johnston BM, Nathanielsz PW (eds) Advances in Fetal Physiology: Reviews in Honor of GC Liggins. Perinatology Press, Ithaca, NY, pp 133-151 